\title{
Active area cell efficiency (19\%) monocrystalline silicon solar cell fabrication using low-cost processing with small footprint laboratory tools
}

\author{
PRABIR K BASU ${ }^{1,2, *}$, SANDEEP KUMBHAR ${ }^{1}$, K P SREEJITH $^{1,3}$, TARUN S YADAV ${ }^{1,3}$, \\ ANIL KOTTANTHARAYIL ${ }^{1,3}$, B M ARORA $^{1}$, K L NARASIMHAN $^{1}$ and ASHOK K SHARMA ${ }^{1}$ \\ ${ }^{1}$ National Centre for Photovoltaic Research and Education (NCPRE), Mumbai 400076, India \\ ${ }^{2}$ Solar Energy Research Institute of India (SERIS), National University of Singapore, Singapore 117574, Singapore \\ ${ }^{3}$ Department of Electrical Engineering, Indian Institute of Technology Bombay, Powai, Mumbai 400076, India \\ *Author for correspondence (prabir.basu@ nus.edu.sg)
}

MS received 28 March 2018; accepted 12 July 2018; published online 2 February 2019

\begin{abstract}
A high efficiency ( $>18 \%$ ) industrial large area crystalline silicon wafer solar cell fabrication process generally requires industrial equipment with large footprint, high capital and running costs. Stricter processing window, continuous monitoring and automated functioning are the reasons for it. However, for any conventional laboratory (lab) it is always difficult to manage these requirements with limited available lab space or insufficient fund and other related resources. In this work, we report a novel way to fabricate high efficiency full area aluminium back surface field monocrystalline silicon wafer solar cells in our lab using low-cost processing with small-footprint fabrication tools for 6 inch pseudo-square industrial wafers. The novelty of our work includes optimization of every fabrication process step, e.g., texturization, emitter diffusion, emitter passivation and anti-reflection coating deposition, edge-isolation, screen printing and co-firing individually. These modifications include tuning of processing tools and processes, utility changes and inclusion of additional process steps. Beaker-based chemical processes, manual diffusion furnace, introduction of low temperature oxidation, low temperature silicon nitride deposition processes, plasma-edge isolation tool, single manual screen printer, single oven drying of metal pastes and co-firing using rapid thermal processing tools were used at our lab. For our cells, actual and active area efficiencies of 18.5 and $19 \%$ (measured under AM1.5G 1 Sun condition), respectively, were achieved.
\end{abstract}

Keywords. Limited laboratory space; small-footprint processing equipment; low-cost processing; individually optimized processes; high-cell efficiency.

\section{Introduction}

The present global photovoltaic (PV) market is dominated by crystalline silicon $(\mathrm{Si})$ wafer solar cells [1]. This domination of crystalline Si necessitates more research to increase the energy conversion efficiency of $\mathrm{Si}$ wafer solar cells in a cost-effective way. This ultimately results in worldwide rapid developmental works in many laboratories in this area of PV. However, initiation of any experimental works of the fabrication of industrial size monocrystalline $\mathrm{Si}$ (c-Si) wafer solar cells requires a laboratory (lab) with all specialized processing equipment. A conventional Si wafer cell fabrication process requires optical engineering by chemical texturization, junction formation by diffusion, the edge or rear side Si etching for parasitic junction removal, passivation and anti-reflection coating (ARC) deposition by plasma enhanced chemical vapour deposition (PECVD), metal paste deposition by screen printing and finally, co-firing of metal contacts in a belt furnace [2]. During texturization, random but uniform pyramids [3] formed on the Si surface to reduce surface reflectance and low-cost alkaline texturing is widely used for texturization of c-Si wafers. Present day $\mathrm{Si}$ cells have uniform and shallow pn junction of $\sim 0.2-0.3 \mu \mathrm{m}$ junction depth over the entire 6 inch pseudo or full square wafer area [4]. Removal of the junction from the rear side, or edges, or both, of the diffused wafer is a critical step to enhance cell open circuit voltage $\left(V_{\mathrm{oc}}\right)$ by minimizing the cell shunt resistance $\left(R_{\mathrm{sh}}\right)$ [2]. The emitter surface passivation layer has dual requirement. It should act as an ARC layer to improve cell short circuit current $\left(I_{\mathrm{sc}}\right)$. It must also act as a passivating layer to improve cell $V_{\mathrm{oc}}$ [5]. The passivated $\mathrm{Si}$ wafers need to be metallized by screen printing of suitable metal pastes, i.e., silver $(\mathrm{Ag})$ paste on an emitter and aluminium (Al) paste on the rear side, followed by a drying and co-firing process to complete the cell fabrication sequence.

The standard equipment involved in the cell fabrication is wet chemical benches, diffusion furnaces, chemical edge isolation tools, PECVD systems, screen printers, belt driers and belt firing furnaces. These tools normally require large space to accommodate them in the lab and additionally some more space for respective chemical/gas delivery and disposal systems. Besides their large footprint, industrial equipment 
Table 1. Footprint of individual tools used for cell fabrication at the NCPRE lab.

\begin{tabular}{|c|c|c|c|c|}
\hline Tool & Process & Tool make and model no. & Quantity & Footprint $\left(\mathrm{m}^{2}\right)$ \\
\hline Wet chemical bench & $\begin{array}{l}\text { Texturization, other } \\
\text { chemical processes }\end{array}$ & $\begin{array}{l}\text { Locally made with white } \\
\text { PP sheet }\end{array}$ & One & 1.6 \\
\hline High temperature quartz furnace & Diffusion, oxidation & Protemp, Sirius PRO 200 & One & 2.7 \\
\hline PECVD & $\begin{array}{l}\text { Passivation and ARC } \\
\text { amorphous } \mathrm{SiN}_{x} \\
\text { deposition }\end{array}$ & $\begin{array}{l}\text { Oxford Instruments, } \\
\text { Plasmalab System } 100\end{array}$ & One & 3.0 \\
\hline Plasma tool & Edge isolation & BSET EQ, NT-2 & One & 1.1 \\
\hline Screen printer & $\begin{array}{l}\text { Printing of } \mathrm{Al} \text { and } \mathrm{Ag} \\
\text { metal pastes }\end{array}$ & Haiku Tech, P200S & One & 1.3 \\
\hline Convention oven & $\begin{array}{l}\text { Drying of } \mathrm{Al} \text { and } \mathrm{Ag} \\
\text { pastes after printing }\end{array}$ & Locally made & One & 0.8 \\
\hline Firing furnace & $\begin{array}{l}\text { RTP furnace for fast firing } \\
\text { of metals }\end{array}$ & Allwin21 Corp., AW 610 & One & 2.0 \\
\hline
\end{tabular}

needs essentially high capital and running costs to produce high-efficiency cells. However, in any conventional research lab, both space constraints and low budget (compared with industry) prevail. This way initiation of any fabrication oriented research on $\mathrm{Si}$ wafer solar cells becomes unfeasible.

The Si solar cell lab at National Centre for Photovoltaic Research and Education (NCPRE), c-Si cell fabrication facility has an area of $160 \mathrm{~m}^{2}$ with small-footprint equipment. The tools include manual wet bench for hosting all the chemical processes with glass beakers and manual controls, semiautomatic diffusion furnace with manual gas-flow and exhaust units, single wafer PECVD system with substrate heating up to $380^{\circ} \mathrm{C}$, plasma-edge isolation, single semi-automatic screen-printer with manual alignment, single convection oven drier and finally a rapid thermal processing (RTP) metal cofiring tool. These tools cannot be compared with sophisticated industrial tools, e.g., inline or batch-based automatic wet benches for chemical processing, large fully automatic diffusion furnace, inline chemical rear-junction isolation bench, inline/tube-based PECVD system with substrate heating up to $450^{\circ} \mathrm{C}$, auto-aligned high-resolution screen-printers each for separate metal printing, separate conveyer-based driers associated with individual screen printers and fast-firing belt furnace contact formation system [2] either cost-wise or in footprint.

Our present work reports the high efficiency cell fabrication process within the lab constraints in a small lab space. The optimization and modifications of each process, processing tools, utilities and accessories to achieve the best possible fabrication conditions on 6 inch pseudosquare $\mathrm{Cz}$ p-type c-Si wafers are discussed in detail along with their characterization results. The new process was applied to fabricate industrial-grade, screen-printed solar cells to produce actual power conversion efficiencies of $18.5 \%$ in our NCPRE cell fabrication lab measured under STC conditions.

\section{Experimental}

\subsection{Fabrication tool footprints}

The footprints of individual tools used for cell fabrication in our lab are listed in table 1. Among the tools, areawise largest tools are our diffusion and PECVD tools with $\sim 3 \mathrm{~m}^{2}$ area. However, these tools are still much smaller than any industrial or pilot line tools. Also, sufficient working space is still available after placing all these tools inside the lab.

\subsection{Cell fabrication}

In the present work, the texturing was performed on a diamond-wire-sawn (DWS) as-cut industrial grade $\mathrm{Cz} \mathrm{c-Si}$ wafers ( 6 inch pseudo-square, boron doped, p-type, (100) orientation, $\sim 1.5-2.5 \Omega \mathrm{cm}$ resistivity, $160-180 \mu \mathrm{m}$ thickness) by using a novel texturing process [6]. Our process combines a novel single step low-cost saw damage removal (SDR) solution of potassium hydroxide $(\mathrm{KOH})$-sodium hypochlorite $(\mathrm{NaOCl})[6]$, followed by pyramidal texturing using $\mathrm{KOH}$, potassium silicate $\left(\mathrm{K}_{2} \mathrm{SiO}_{3}\right)$ and isopropyl alcohol (IPA) solution [3]. Textured wafers were diffused for a target sheet resistance $\left(R_{\mathrm{sq}}\right)$ of $80 \Omega \mathrm{sq}^{-1}$ in a tube diffusion furnace (Protemp USA, Sirius PRO 200) using a liquid phosphorus oxychloride $\left(\mathrm{POCl}_{3}\right)$ dopant source for phosphorous $(\mathrm{P})$ diffusion. After dipping in a $2 \%$ hydrofluoric acid (HF) solution for phosphosilicate glass (PSG) removal, the wafers were oxidized to form silicon dioxide $\left(\mathrm{SiO}_{2}\right)$ in a low temperature thermal oxidation (LTO) process in the same furnace for $1 \mathrm{~h}$ at $600^{\circ} \mathrm{C}$. Amorphous silicon nitride $\left(\mathrm{SiN}_{x}\right)$ passivation (which also acts as an ARC layer) was then deposited by PECVD using an Oxford Instruments, Plasmalab System 100 tool at $380^{\circ} \mathrm{C}$. The deposited $\mathrm{SiN}_{x}$ film has a refractive index of 2.00 (at $633 \mathrm{~nm}$ ) and a thickness of $90 \mathrm{~nm}$ as measured on our 


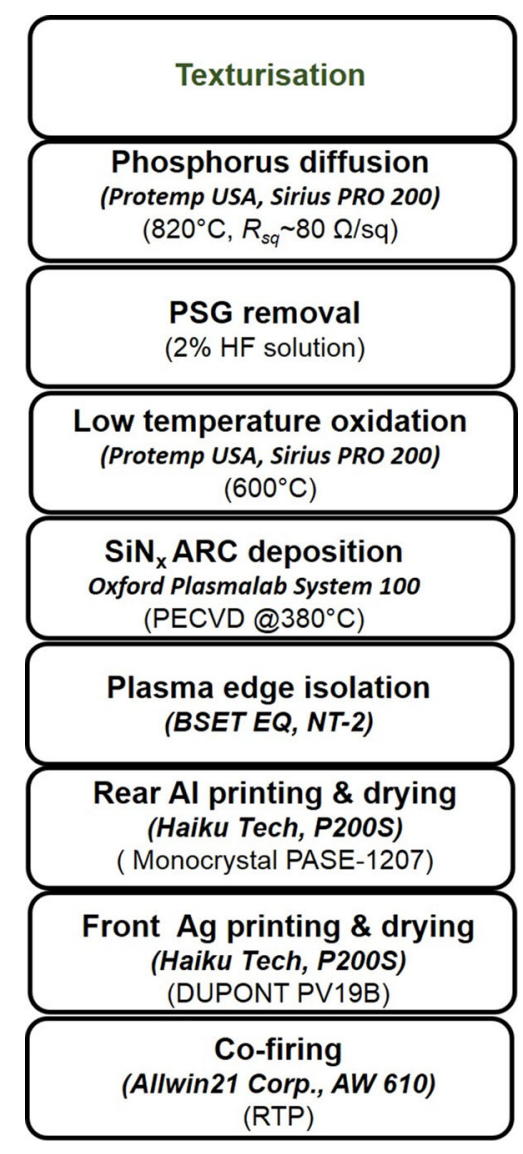

Figure 1. Schematic illustration of the solar cell processing flow used in this work.

test sample of polished c-Si wafer. After dielectric deposition, removal of a pn junction from the wafer edges was carried out in a plasma-edge isolation tool (BSET EQ, NT-2). Finally, Al rear and $\mathrm{Ag}$ front contacts were formed by screen printing (Haiku Tech, P200S). Once dried in an oven, they were subsequently co-fired in an RTP unit (Allwin21 Corp., AW 610). A summary of the solar cell fabrication sequence is shown in figure 1.

\subsection{Fabrication of lifetime test samples}

Symmetrically doped test structures for lifetime measurements were fabricated on the representative textured wafers to help in process optimization. Tube-based P-diffusion was carried out on both sides of the wafers followed by the PSG etch. After LTO at $600^{\circ} \mathrm{C}$ for $1 \mathrm{~h}$, a passivating layer of $\mathrm{SiN}_{x}$ (as mentioned in section 2.2) was deposited on both sides of all the lifetime samples followed by RTP firing at a cell firing temperature profile. Excluding the LTO step, another set of lifetime samples was also fabricated. The process flow of fabrication of lifetime samples in both the cases is shown in figure 2 .

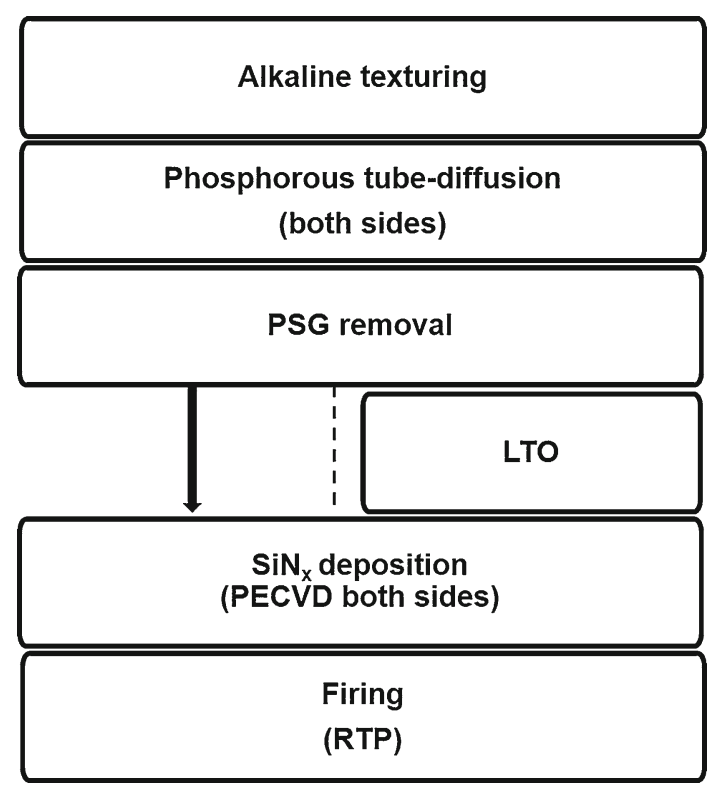

Figure 2. Lifetime sample fabrication process flow for the c-Si wafers with or without an LTO process.

\subsection{Characterization details}

For the surface morphological studies on the representative textured wafer (cleaned in IPA, followed by de-ionized water (DIW) rinsing and drying), a scanning electron microscope (SEM, model: Zeiss Ultra 55) was used. Quantitative analysis of pyramid formation was performed using a Zeta Instruments optical microscope (ZETA-20). Textured surface reflectance was measured using a spectrophotometer (Perkin Elmer, Lambda 950). For calculation of the weighted average of reflectance (WAR), textured surface reflectance was measured using a $150 \mathrm{~mm}$ diameter integrating sphere weighted using the AM1.5G solar spectrum over the wavelength $(\lambda)$ range of 300-1000 nm. Conformity of emitter diffusion on diffused c-Si wafers was assessed by a four-point probe tester (Jandel, MHP-12 \& Multi-PT8) by $R_{\mathrm{sq}}$ map generated with 49 point measurements. The active dopant impurity profile was measured using an electrochemical capacitance-voltage (ECV) analyser (WEP CVP21). A lifetime tester (Sinton Instruments, WCT-120) was used for the measurement of effective minority carrier lifetime $\left(\tau_{\text {eff }}\right)$ of the symmetric lifetime samples. A customized photoluminescence (PL) setup consisting of LED-based excitation at the $\lambda$ of $630 \mathrm{~nm}$ was used for PL imaging of lifetime samples. An 8.3 megapixel Si CCD camera coupled with spectrally designed filters was used to capture luminescence images. A Class AAA solar simulator (Abet Technologies, Sun 3000) was used to measure the illuminated current-voltage $(I-V)$ characteristics of the final solar cells under STC $\left(1000 \mathrm{~W} \mathrm{~m}^{-2}\right.$, AM1.5G spectrum and $25^{\circ} \mathrm{C}$ cell temperature) against a calibrated reference cell. The internal and external quantum efficiencies (IQE and EQE) of 

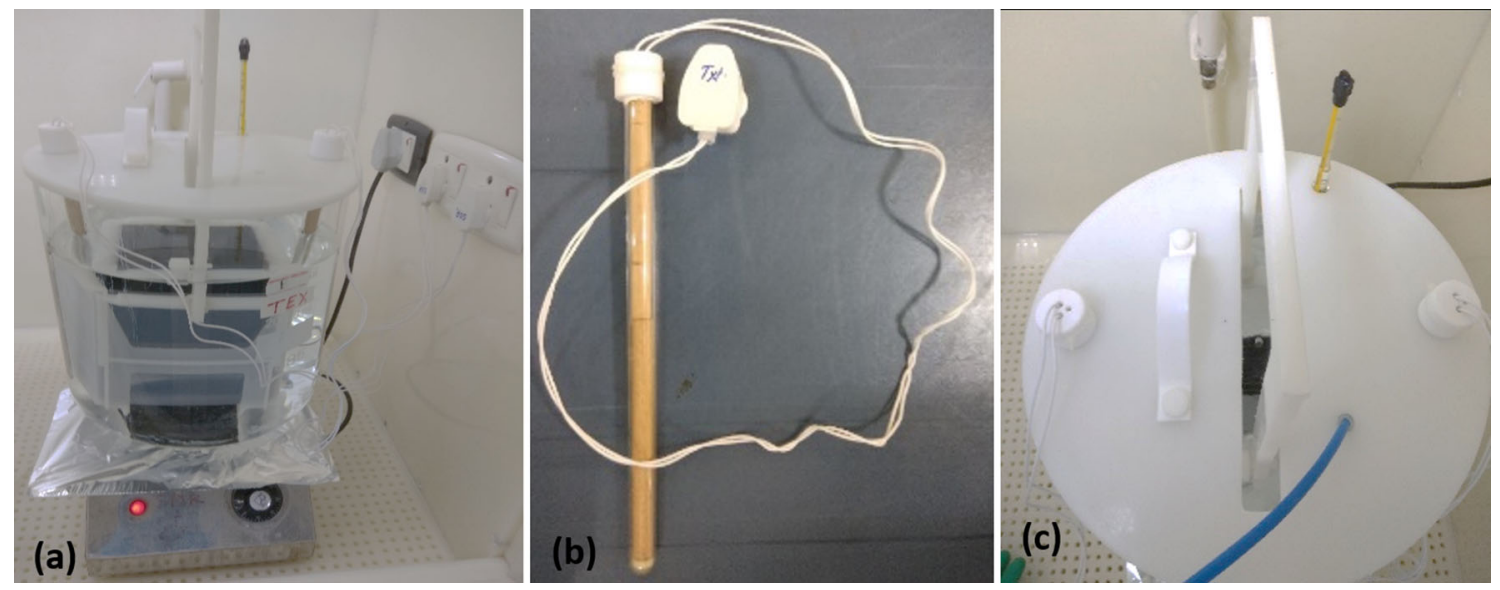

Figure 3. Images of texturing: (a) photo of the complete experimental arrangement of the SDR/texturing/neutralization process; (b) photo of the cylindrical immersion heater and (c) photo of the designed PP cover of the glass beakers. The cover has holes/empty spaces of appropriate dimensions to hang cylindrical heaters, thermometer holder, blue $\mathrm{N}_{2}$ gas pipe and rectangular hole to draw or take out the handle of the wafer carrier.

cells were measured using a Bentham PVE 300 tool over the 300-1200 nm wavelength range.

\section{Results and discussion}

The details of the improvizations carried out in the tools/ apparatuses used in the lab with specific process steps and related characterization results are discussed below.

\subsection{Fabrication process steps}

3.1a Texturization: Large glass beakers (Borosil, 20 litre volume) were used for SDR, texturing and neutralization processes. Rectangular single chamber polypropylene (PP) bath and cascade double chamber PP bath were fabricated for $2 \%$ HF dip and DIW rinsing processes, respectively. The complete arrangement for the texturing process is shown in figure $3 \mathrm{a}$. The glass beakers were heated from the bottom by a hot plate and two additional cylindrical heaters were used. These vertical heaters were made locally with heating coils concealed in a quartz tube (figure $3 b$ ) hanged from the top of the beaker through a specially designed PP cover tray (figure $3 a$ ). A thermometer was kept inside a DIW-filled quartz test tube and was suspended from the cover in the chemical solution for temperature measurement (figure 3a). The texturing bath/beaker was covered properly by designing its cover (white PP) to minimize the loss of chemicals (especially IPA) during the process. Besides, holes were made through it to allow the hanging of heaters, thermometer and a tube for nitrogen gas as mentioned earlier. During the heating of the texturing solution, nitrogen gas was bubbled through the solution to reduce the temperature gradient and to make the solution homogeneous. For our DWS c-Si wafers, a novel single step pre-cleaning and SDR process using $\mathrm{KOH}$ ( $8 \%$ by weight) and $\mathrm{NaOCl}$ solutions in a ratio of 1:1 (by volume) was applied for 3 min duration at a temperature of $80^{\circ} \mathrm{C}$ [6]. For the pyramidal texturing, the silicate-based low-IPA texturing process [3] was used. Temperature of the texturing solution was maintained at $80^{\circ} \mathrm{C}$ during texturing by manual switching on/off the heaters. The amount of Si removed during the texturing process was calculated by measuring the weight of the wafer before and after the texturing process.

Figure 4a shows the SEM images (angular view) of the pyramidal structure formed on our DWS Si wafer surface after 20 min texturing time. This magnified $(5000 \times)$ image of the surface depicts the formation of a uniform pyramidal surface with no existence of any visible saw-marks or any nonpyramidal space on the textured wafer surface. The statistics of the pyramid heights were obtained using a Zeta 3D microscope over the field of view of $95 \times 71 \mu \mathrm{m}$ and is shown in figure $4 \mathrm{~b}$. The average pyramid height is estimated to be $\sim 2.2-2.3 \mu \mathrm{m}$ with a standard deviation (STDEV) of $0.6 \mu \mathrm{m}$. These data confirm the formation of small but uniform pyramids over the S-wafer surface within our lab setup.

Wavelength dependence of $R$ of the representative pyramidally textured $\mathrm{c}-\mathrm{Si}$ wafer is shown in figure 5 before and after ARC deposition. The surface reflectance graphs along with their low WAR values (WAR of $13.4 \%$ after texturing and WAR of $2.3 \%$ after ARC deposition) further confirm excellent optical properties of the textured surfaces.

3.1b Diffusion: High efficiency c-Si cell fabrication requires a uniform and shallow emitter with controlled Pdiffusion in a tube diffusion furnace. Achieving diffusion uniformity thus requires proper recipes with correct combination of the process temperature, gas flow dynamics, gas volumes and a matching process gas exhaust. During our optimized process, the furnace exhaust has been modified to allow an optimum outflow. Optimization of flow dynamics 

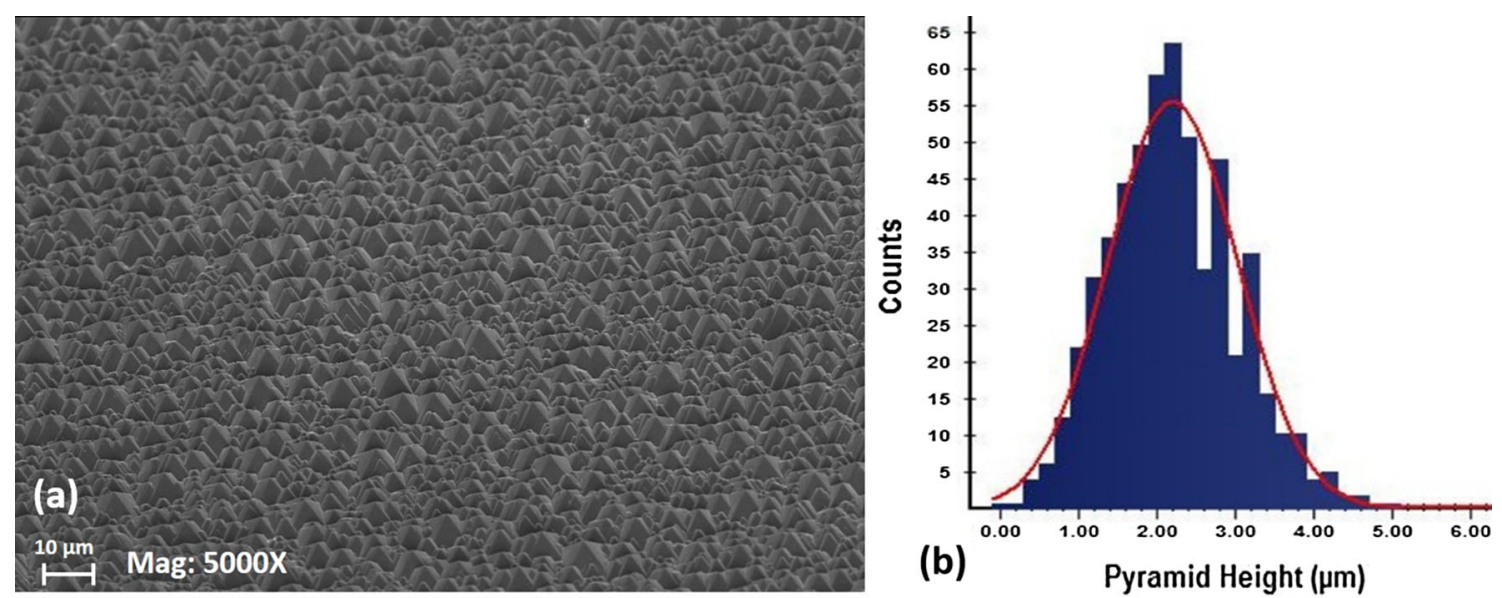

Figure 4. Optical study of the pyramidally textured surface: (a) SEM micrograph of the final textured c-Si wafer surface $\left(45^{\circ}\right.$ angular view; magnification: $\left.5000 \times\right)$ and (b) Zeta 3D measurement data of pyramid height distribution for our textured c-Si wafer.

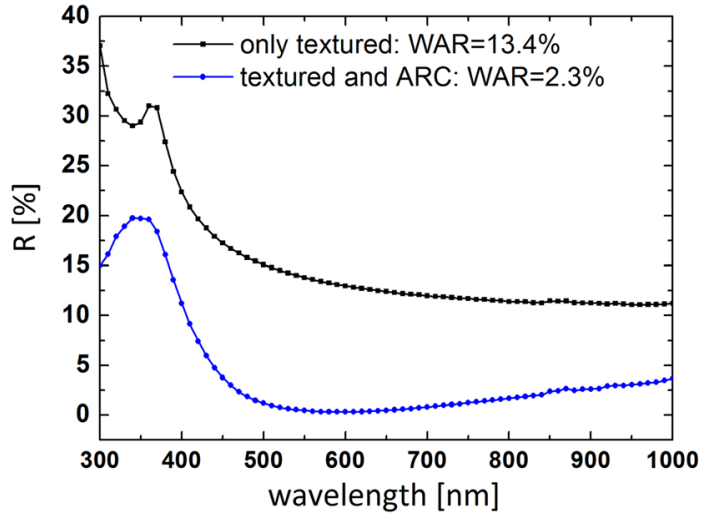

Figure 5. Variation of emitter surface reflectance $(R)$ on the alkaline textured c-Si wafers after our texturing process and after $\mathrm{SiN}_{x}$ ARC deposition over 300-1000 nm wavelength range.

within the diffusion tube requires a balance between the in-flow rate (from furnace input end) and out-flow rate (from furnace exhaust end) of gases. The correct balance does not allow any leakage of $\mathrm{POCl}_{3}$ vapour from the furnace into the clean room. However, it gives process gases enough time (within hot zone inside the furnace) for uniform diffusion on the large area wafers inside the diffusion tube.

Initially the existing quartz outlet at the end of the loader had a wider gap (figure 6a) and this allowed most of the process gases to be exhausted. This resulted in non-uniform diffusion along a single wafer and also wafer-to-wafer in the same diffusion lot. An additional quartz plate (5 $\mathrm{mm}$ thick) with five holes (figure 6b) was designed and fitted just in front of the exhaust outlet (figure $6 \mathrm{c}$ and d) on the loader. This way furnace exhaust area was reduced to achieve better uniformity of diffusion. Also after unloading of the diffused wafers, as seen in figure $6 \mathrm{~d}$, no visible displacement or gap was observed between the new quartz plate and the large originally fixed quartz plate. The temperature profile along the length of the diffusion tube was measured with a profiling thermocouple to determine the uniform temperature zone suitable for uniform diffusion.

The gas flows were optimized by several trials till the desired diffusion uniformity was achieved. Our optimized diffusion recipe with typical process gas flows is shown in figure 7. Two-step diffusion was used in our recipe to have a low dopant concentration at the emitter surface (with no or minimum dead layer [2] and deeper junction). Auger recombination increases strongly above the concentration of $\sim 10^{17} \mathrm{~cm}^{-3}$; the reduced area under the curve above $10^{19} \mathrm{~cm}^{-3}$ is an indication of a reduced Auger recombination level for the emitters [2]. This recipe helps to have a deeper and uniform emitter junction with low dopant concentration on the entire area of the c-Si wafer surface. This deeper junction helps in achieving a reliable metallization process without impairing the junction with limited capability lab tools. The uniformity of the emitter surface is characterized by the $R_{\mathrm{sq}}$ map and is shown in figure 8a.

The average (ave) $R_{\mathrm{sq}}$ value of $81 \Omega \mathrm{sq}^{-1}$ with a STDEV of $1.9 \Omega \mathrm{sq}^{-1}$ (measured over 49 points) for the P-diffused emitter in the NCPRE diffusion furnace shows formation of an excellent emitter for our cell. The distribution of $\mathrm{P}$ dopants during our $\mathrm{P}$ diffusion process is studied by ECV and the dopant profile is shown in figure $8 \mathrm{~b}$. The peak dopant concentration is $\sim 2.4 \times 10^{20} \mathrm{~cm}^{-3}$ and the junction depth is $\sim 0.30 \mu \mathrm{m}$. Here we have used a dopant concentration of $1 \times 10^{17} \mathrm{~cm}^{-3}$ as an approximate value of the end of the emitter junction for all the diffused wafers as a reference for the calculation of the junction depth [7].

3.1c Surface passivation: The conventional process of surface passivation of P-doped c-Si wafers is by the deposition of $\mathrm{SiN}_{x}$ in the PECVD process [5]. This layer must provide an emitter surface passivation and simultaneously also act as 

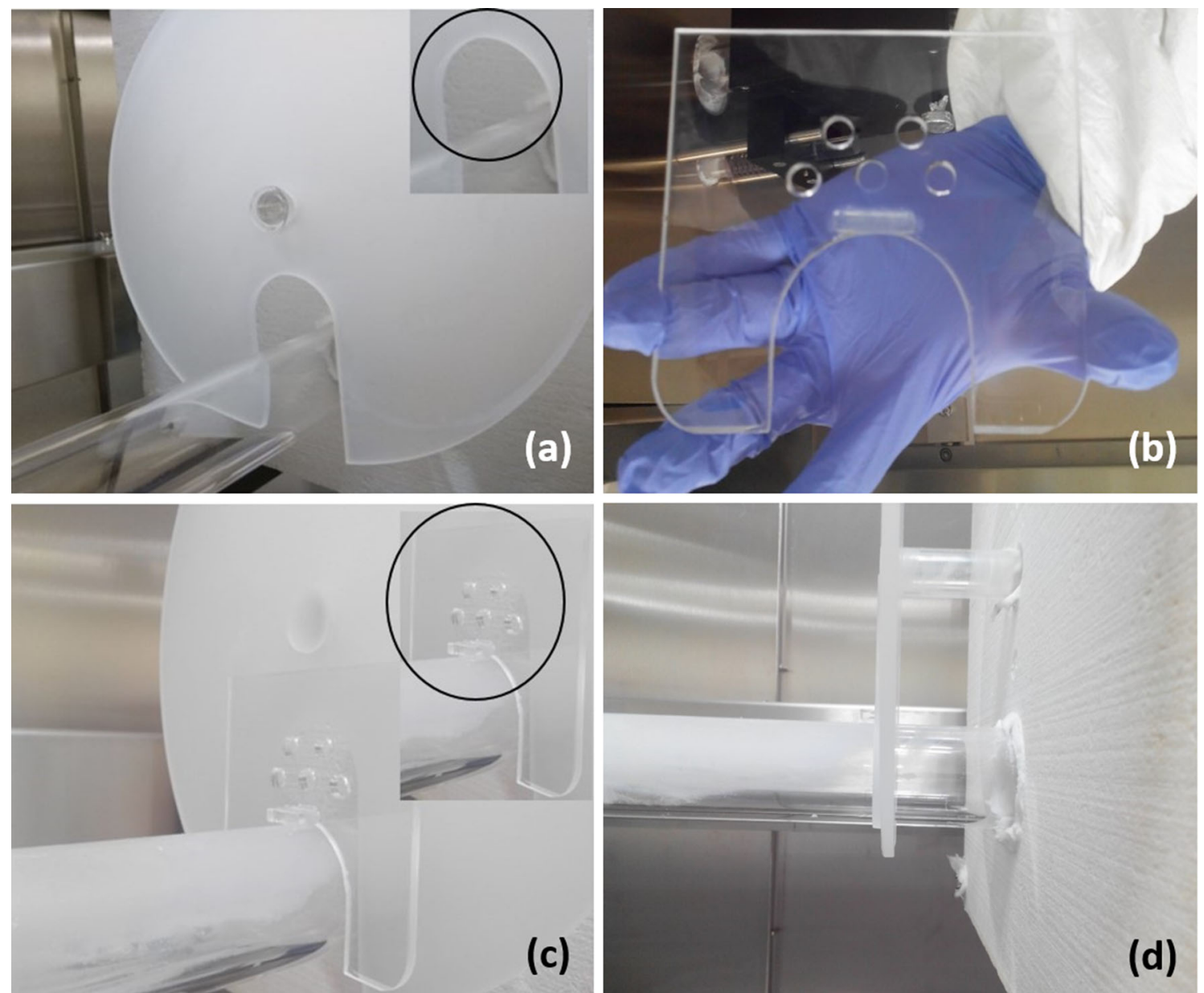

Figure 6. Photos of the diffusion exhaust port at different scenarios: (a) the exhaust outlet port (viewed from inside after unloading the loader) originally present. The inset shows the amount of gap left for suction (circled) by the exhaust. (b) Our designed quartz plate with five holes $(1 \mathrm{~cm}$ diameter each). (c) The modified exhaust outlet port (viewed from inside after unloading the loader) after placing the additional quartz plate. The inset shows the reduced amount of gap left for suction (circled) by the exhaust. (d) The side view of the modified exhaust port. No visible gap is observed between the two quartz plates.

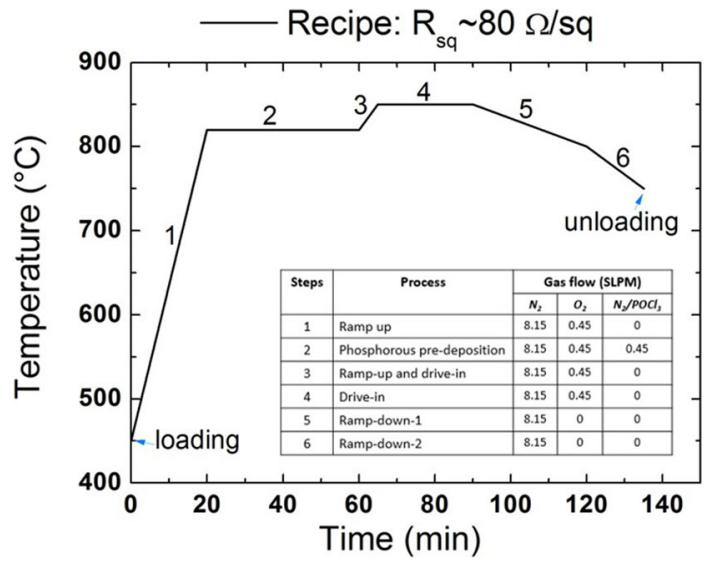

Figure 7. The diffusion recipe of our two-step diffusion process. The table in the inset shows gas flows during respective steps in diffusion. an ARC layer. Our PECVD $\operatorname{SiN}_{x}$ deposition was performed for $3 \mathrm{~min}$ at the substrate temperature of $380^{\circ} \mathrm{C}$. During the process, silane, ammonia and carrier gas flows were 25,20 and $980 \mathrm{sccm}$, respectively, for $390 \mathrm{~s}$ (RF power of $20 \mathrm{~W}$ and chamber pressure of $650 \mathrm{mTorr}$ ). The passivation properties were analysed by the values of the lifetime parameters, i.e., $\tau_{\text {eff }}$, implied open circuit voltage $\left(i V_{\text {oc }}\right)$ and emitter reverse saturation current density $\left(J_{0 \mathrm{e}}\right)$. The lifetime parameter values were measured using the Sinton tool after dielectric depositions and are shown in table 2.

After PECVD SiN $x$ deposition in our tool, the values of $\tau_{\text {eff }}$ and $i V_{\mathrm{oc}}$ are quite low. The reason behind this in our PECVD tool is that it is limited by the maximum achievable substrate temperature of $380^{\circ} \mathrm{C}$. However, the conventional process for passivation of the P-diffused emitter on the c-Si surface is by the deposition of $\mathrm{SiN}_{x}$ of proper thickness and refractive index at $450^{\circ} \mathrm{C}$ [2]. These low values of $\tau_{\text {eff }}$ and $i V_{\text {oc }}$ in our 

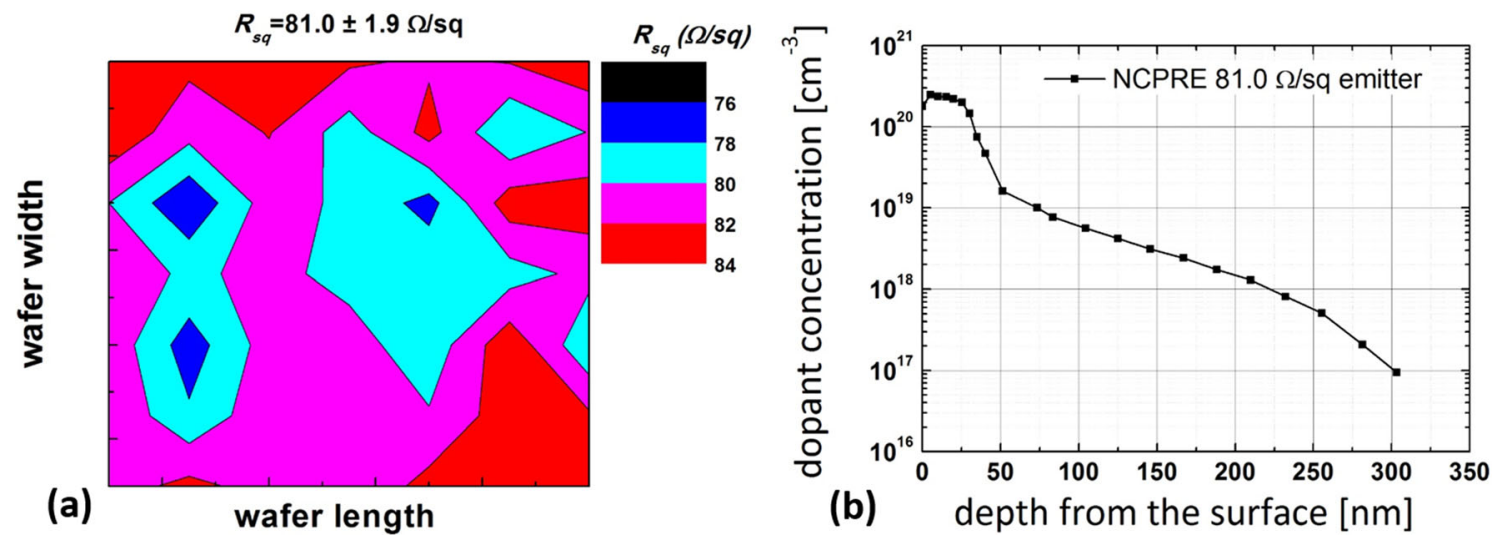

Figure 8. (a) $R_{\mathrm{sq}}$ map for the tube-diffused c-Si wafers (ave $\sim 81.0 \Omega \mathrm{sq}^{-1}, \mathrm{STDEV} \sim 1.9 \Omega \mathrm{sq}^{-1}$ ). The measurements were made using a four point probe on a $7 \times 7$ matrix with $1.5 \mathrm{~cm}$ edge exclusion and (b) active dopant impurity profiles (measured by ECV) of our tube diffused emitter.

Table 2. Variation of lifetime parameters of the $\mathrm{SiN}_{x}$-deposited and double-layer dielectrics of thermal $\mathrm{SiO}_{2}-\mathrm{SiN}_{x}$ samples.

\begin{tabular}{|c|c|c|}
\hline Lifetime parameters & Only PECVD $\mathrm{SiN}_{x}$ deposition & Thermal $\mathrm{SiO}_{2}$ and PECVD $\mathrm{SiN}_{x}$ deposition \\
\hline$\tau_{\text {eff }}(\mu s)$ & 37.5 & 61.1 \\
\hline$i V_{\mathrm{oc}}(\mathrm{mV})$ & 633 & 646 \\
\hline$J_{0 \mathrm{e}}\left(\mathrm{A} \mathrm{cm}^{-2}\right)$ & $2.2 \times 10^{-13}$ & $1.5 \times 10^{-13}$ \\
\hline
\end{tabular}

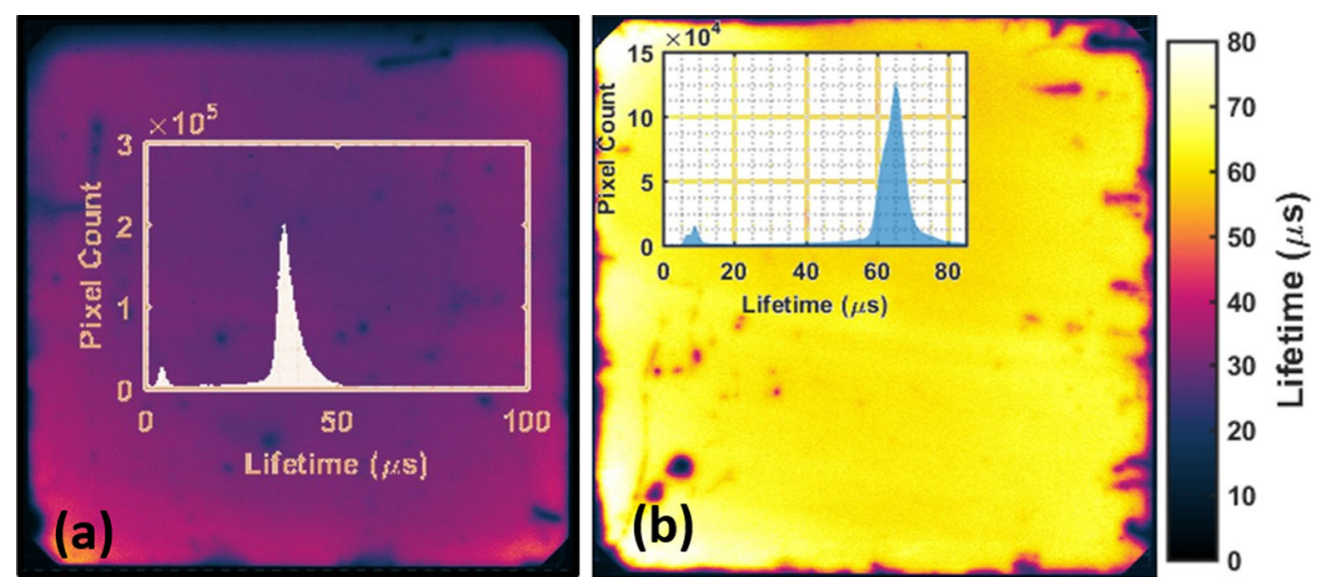

Figure 9. Spatially resolved PL images of textured $\mathrm{n}^{+}-\mathrm{p}-\mathrm{n}^{+} \mathrm{c}-\mathrm{Si}$ lifetime samples of (a) both $\operatorname{side} \operatorname{SiN}_{x}$ layer only and (b) both side $\mathrm{SiO}_{2}-\mathrm{SiN}_{x}$ layers.

tool reflect poor passivation by the deposited dielectric layer of only $\mathrm{SiN}_{x}$. In order to improve surface passivation in our diffused wafers, we incorporated LTO prior to $\mathrm{SiN}_{x}$ deposition. A combination of $\sim 4 \mathrm{~nm}$-thick $\mathrm{SiO}_{2}$ layer grown on a Si-emitter (at $600^{\circ} \mathrm{C}, 1 \mathrm{~h}$ ) and our PECVD $\operatorname{SiN}_{x}\left(\right.$ at $380^{\circ} \mathrm{C}$ ) resulted in higher values of $\tau_{\mathrm{eff}}$ and $i V_{\mathrm{oc}}$ and lower value of $J_{0 \mathrm{e}}$ (see table 2). These values indicate better passivation of the emitters by our $\mathrm{SiO}_{2}-\mathrm{SiN}_{x}$ layers.

A comparison between the quality of emitter passivation achieved by the two-passivation processes, without and with an interfacial LTO layer, was also studied by our PL imaging tool. PL images were taken for the representative wafers (similar structure to the lifetime samples) and the PL images were converted then into the carrier lifetime map using calibration of PL pixel intensity with measured QSSPC carrier lifetime values [8].

Figure $9 \mathrm{a}$ and $\mathrm{b}$ shows the lifetime maps of $\mathrm{SiN}_{x}$-deposited and double-stack dielectric of thermal $\mathrm{SiO}_{2}-\mathrm{SiN}_{x}$ samples, respectively. The $\mathrm{SiO}_{2}-\mathrm{SiN}_{x}$-deposited sample has a brighter image with higher $\tau_{\text {eff }}$ values as compared with only 


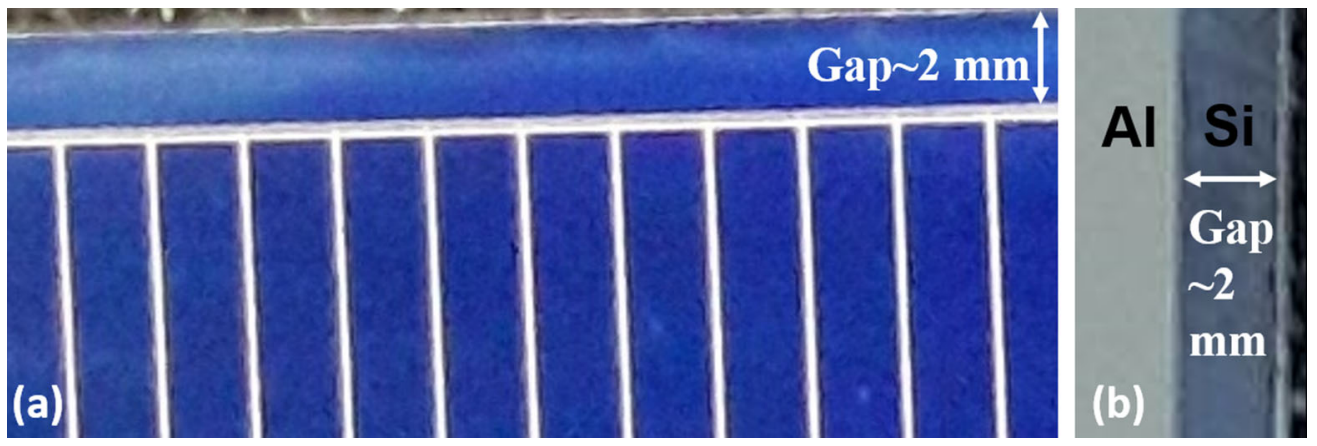

Figure 10. Photos of the printed cells: (a) front Ag-printed position of cell along the cell edge and (b) rear Al-printed position of cell along the cell edge. In both the cases, $\sim 2 \mathrm{~mm}$ width of Si remains non-metallized.

$\mathrm{SiN}_{x}$-deposited one. Besides, both the images are very uniform in their distribution of $\tau_{\text {eff }}$ values all over the wafer areas. This reflects the uniformity and effectiveness of our novel passivation process even with the limitations of lowplasma temperature of $380^{\circ} \mathrm{C}$. The insets of figure $9 \mathrm{a}$ and $\mathrm{b}$ show the distribution of $\tau_{\text {eff values throughout the entire wafer }}$ surfaces and these indicates a narrower distribution of $\tau_{\text {eff }}$ in both the cases with only $\mathrm{SiN}_{x}$ and double-stack $\mathrm{SiO}_{2}-\mathrm{SiN}_{x}$ dielectric-deposited samples.

After final ARC deposition of $\mathrm{SiN}_{x}$, the surface reflectance variation on the representative textured (also diffused and oxidized) c-Si wafer is shown in figure 5. These spectral reflectance values for the ARC wafers with low value of WAR $(\sim 2.3 \%)$ confirm excellent optical properties for our dielectric deposition process.

3.1d Junction isolation: Effective removal of a parasitic junction from the edge is critical to decrease the influence of shunt resistance $\left(R_{\mathrm{sh}}\right)$. At present, complete rear junction removal in an acidic solution [9] is the standard industrial process. However, these acid-based inline rear junction isolation tools are non-affordable in a low-cost and small-footprint lab like ours. The alternate option thus chosen in our case is a plasma-edge isolation tool using sulphur hexafluoride $\left(\mathrm{SF}_{6}\right)$ gas. Our process can effectively etch a P-doped Si layer along the edges of the diffused wafer with an approximate etch width of $<1 \mathrm{~mm}$. High values of $R_{\mathrm{sh}}\left(>15 \mathrm{k} \Omega \mathrm{cm}^{2}\right)$ measured from the dark $I-V$ characteristics of our cells further confirm our optimized edge isolation process.

3.1e Metallization: Screen printed contacts were used for front $\mathrm{Ag}$ and back $\mathrm{Al}$ metallization of our cells. The front screen has been designed using Griddler simulation [10] for a proper conducting Ag-paste. However, our low-cost screen printer has several limitations. It cannot print $<60 \mu \mathrm{m}$ finger width, squeeze pressure is not uniform over the whole 6 inch pseudo-square wafer surface during printing and the wafer alignment process is completely manual. Under these limitations, printing is restricted to using front screen

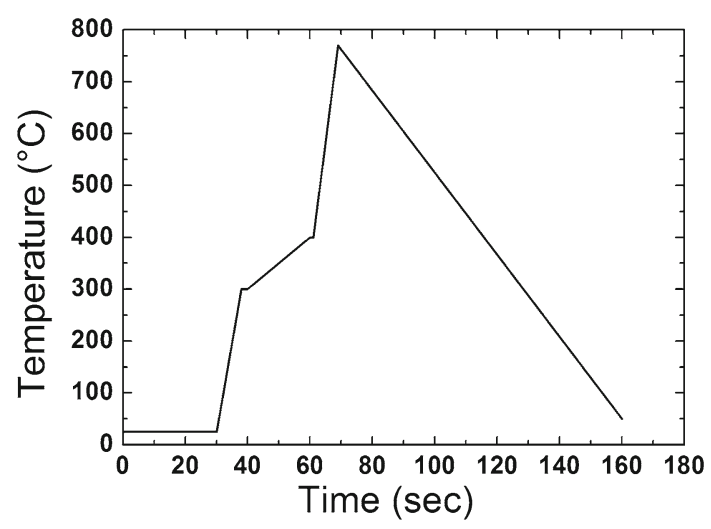

Figure 11. The RTP firing profile used with a peak temperature of $770^{\circ} \mathrm{C}$.

with $60 \mu \mathrm{m}$ finger width with optimized squeeze speed and pressure. Besides, in our screen design, edge-exclusion of $\sim 2 \mathrm{~mm}$ was maintained to avoid edge shunting during printing of $\mathrm{Ag}$ paste (figure 10a) on the edge-etched (during plasma-edge isolation) p-type Si part of the wafer. Similar design was also used for the rear side contact printing (figure 10b).

After Al-paste printing, printed wafers were dried in a convection oven with gases of $\mathrm{N}_{2}$ and $\mathrm{O}_{2}$ in a ratio of 4:1. Similarly, Ag-paste printing was followed by drying in the same oven. The RTP co-firing temperature profile setting with a peak temperature of $770^{\circ} \mathrm{C}$ is shown in figure 11 . After achieving the peak temperature rapid cooling has been designed to reach room temperature for unloading. Care was taken not to allow any $\mathrm{Al}$ ball generation at the rear side of the finished cell.

The cross-sectional SEM micrograph of the cell rear surface after printing and firing is shown in figure 12. Nearly $7.7 \mu \mathrm{m}$ thick $\mathrm{p}^{+}$-back-surface field (BSF) region is clearly visible and this amount of BSF layer is sufficient for highefficiency cells. 

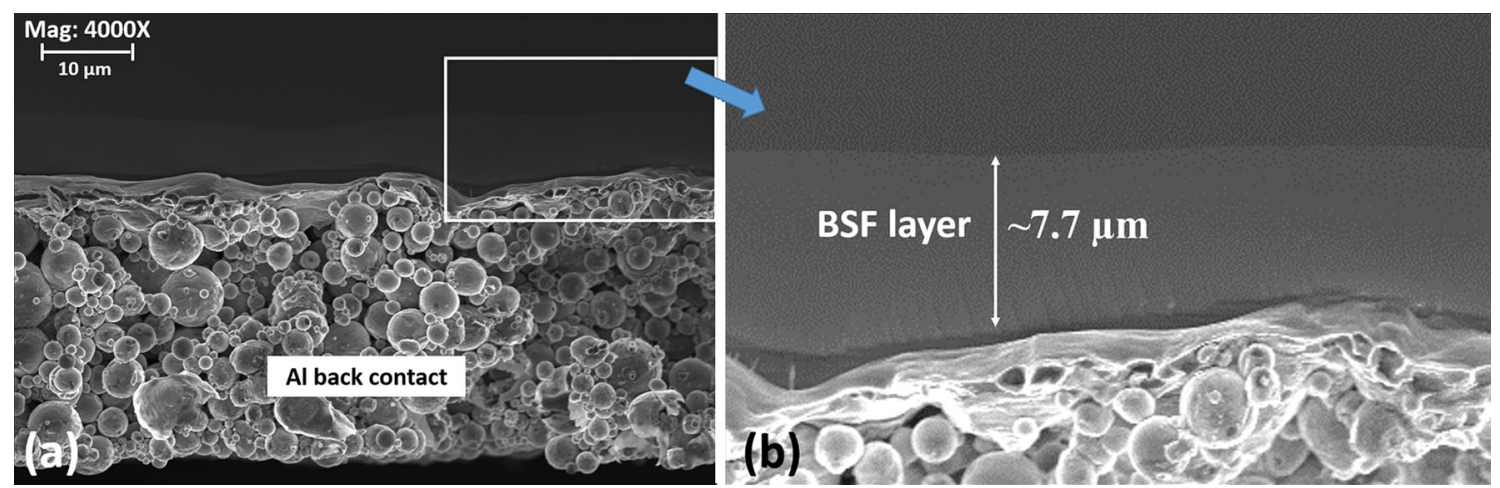

Figure 12. SEM micrograph (cross-sectional) of the rear Al-metallized portion of the cell: (a) the as-obtained image with magnification: $4000 \times$ and (b) magnified image of the enclosed rectangular portion of the image (a) with modified contrast to observe/detect the $\mathrm{p}^{+}$-BSF layer.

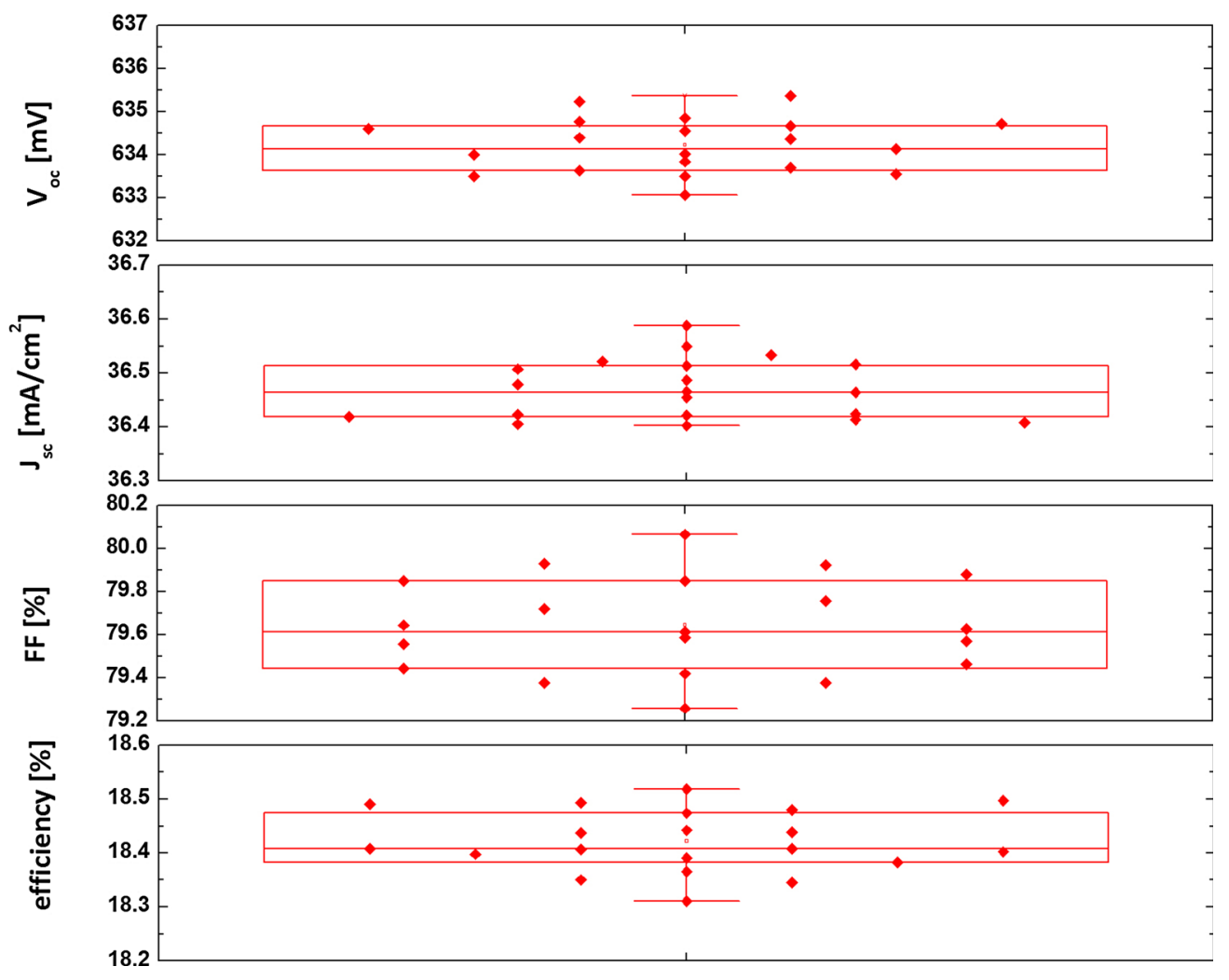

Figure 13. Cell parameter distribution of a complete lot showing the variations of $V_{\mathrm{oc}}, J_{\mathrm{sc}}, \mathrm{FF}$ and efficiency.

\subsection{Completed solar cell performance}

The variation of cell electrical parameters of a complete lot of 20 cells is shown in figure 13. The efficiency range lies within the $\sim 18.3-18.5 \%$ range and several cells achieved $\sim 18.5 \%$ efficiency. For comparison, we also measured a standard industrial screen printed full area BSF Si solar cell. The $\mathrm{EQE}, \mathrm{IQE}$ and emitter reflectance $(R)$ of one of the best cells and the standard industrial cell are shown in figure 14. Higher short-wavelength and little better long-wavelength spectral responses of the standard cell indicate excellent equipment with better processing conditions for cell fabrication in the industry as compared with our lab. The inset also shows the electrical parameters of the best NCPRE cell and the standard industrial cell with their $I-V$ characteristics. Reasonable good values of $V_{\mathrm{oc}}$ and fill factor (FF) of the cell along with moderate value of $J_{\mathrm{sc}}$ (in figure 14) show good processing conditions at our cell fabrication lab. 
Comparatively moderate or low value of $J_{\mathrm{sc}}$ is analysed as normally any good BSF c-Si cells must have $J_{\mathrm{sc}}>$ $37 \mathrm{~mA} \mathrm{~cm}^{-2}$ (as seen in figure 14 for the standard industrial cell). The reason lies in the absence of the wafer alignment procedure in our manual screen printer. Considering $\sim 0.5 \mathrm{~mm}$ edge exclusion of any industrial cells, we used higher-edge exclusion. So, approximately $8 \mathrm{~cm}^{2}$ of the rear and front sides of the active region is not getting printed. This area is not contributing to current collection. If we can theoretically consider the active area after the reduction of $8 \mathrm{~cm}^{2}$, the active area $J_{\mathrm{sc}}$ and efficiency values changed to $\sim 37.5 \mathrm{~mA} \mathrm{~cm}^{-2}$

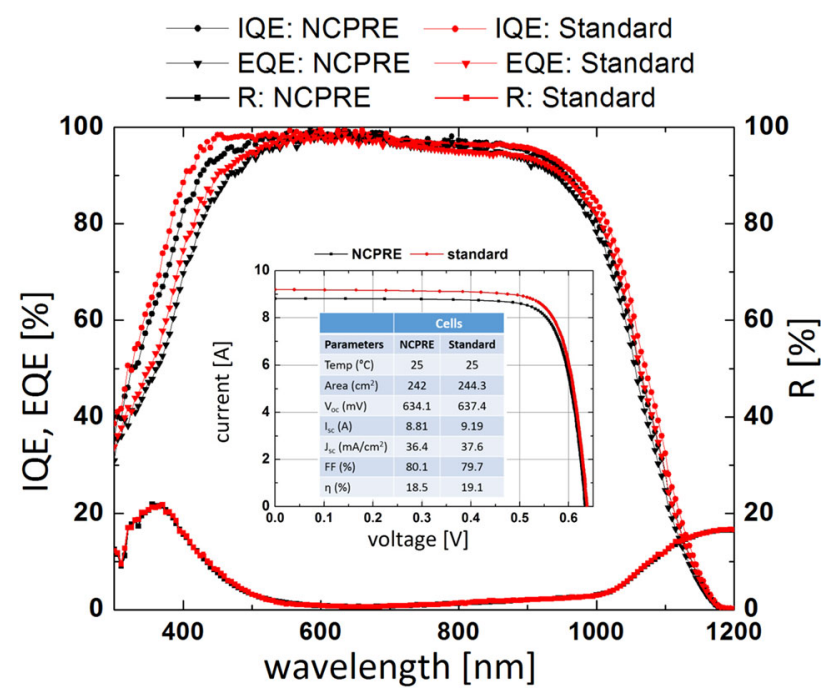

Figure 14. Comparative plots of EQE, IQE and emitter reflectance $(R)$ of one of the best NCPRE cells with standard industrial printed solar cells. The inset shows the electrical parameters along with the $I-V$ characteristics of the NCPRE best cell and the standard industrial cell. and $\sim 19.0 \%$, respectively. Besides, under that condition, due to better metal coverage all over the printed cell, FF values will also be improved. Also, as seen in figure $15 \mathrm{a}$ and $\mathrm{b}$, the spreading of the $60 \mu \mathrm{m}$ fingers after printing and firing are within the $88-92 \mu \mathrm{m}$ range and the finger height is $15.6 \mu \mathrm{m}$.

This additional spreading of $\sim 30 \mu \mathrm{m}$ or more in our printing process is not desirable as it enhances shadowing. Also, it decreases the finger height to reduce its aspect ratio. Thereby, just by using a better screen printer with auto-aligned facility, our metallization process will improve to stretch our cell efficiency beyond $19 \%$.

\section{Conclusions}

An improved way of fabricating large area industrial $\mathrm{Si}$ wafer solar cells is developed by using small-footprint lowcost fabrication tools inside a small lab area of $160 \mathrm{~m}^{2}$. During this work, every process step has been optimized individually to obtain the maximum output from each equipment and related process in spite of our lab limitations. The alkaline texturization process and accessories have been modified to generate uniform but small pyramids required to fabricate high-efficiency cells. Modifications have been introduced in the NCPRE diffusion tube gas flow dynamics furnace and in the diffusion recipes to facilitate conformal pn junction formation all over the wafer surface with the required dopant impurity profile. An additional LTO process was introduced before the PECVD $\mathrm{SiN}_{x}$ deposition process to improve cell passivation qualities. Plasma-based junction isolation along the wafer edges, screen printing in a single semi-automatic printer, paste drying in a single convection oven and co-firing in the RTP furnace has also been optimized to achieve excellent cell electrical
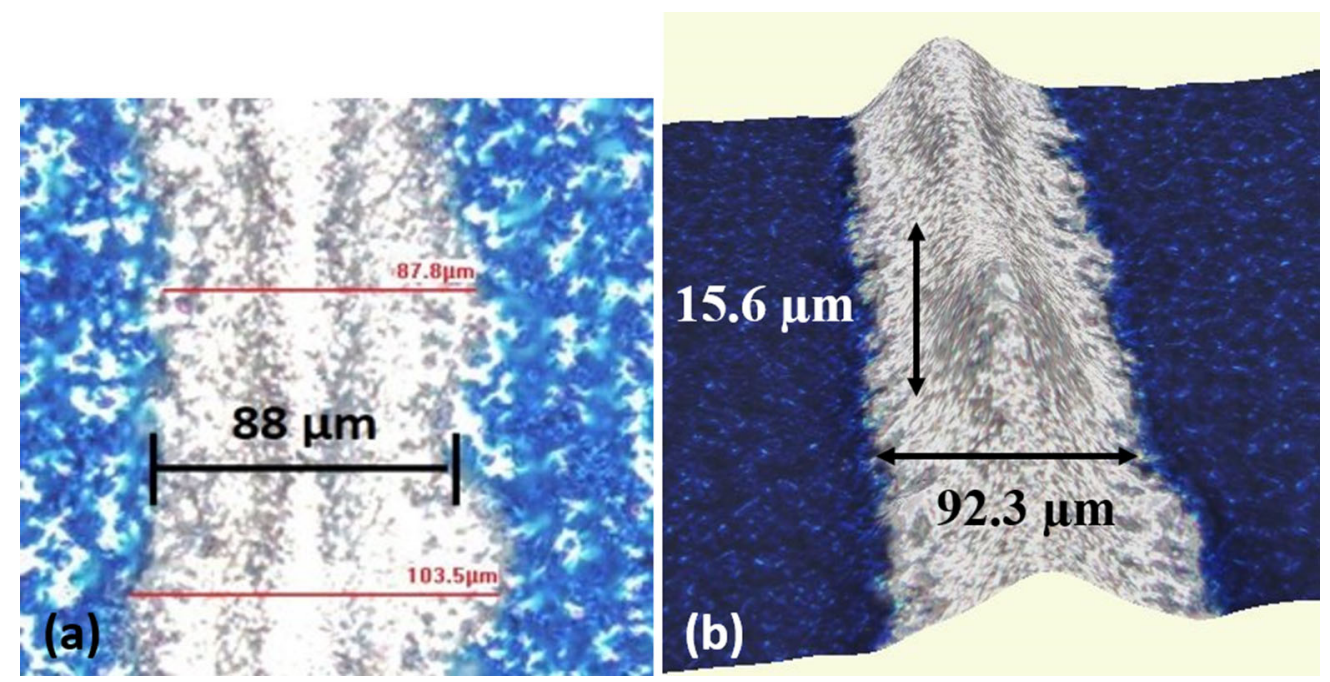

Figure 15. Zeta 3D microscopic images of NCPRE printed Ag-finger: (a) 2D normal view and (b) 3D angular view. 
parameters. All the above developments finally led us to fabricate 6 inch pseudo-square DWS Cz industrial Si solar cells of actual and active area efficiencies of 18.5 and $19 \%$ (under AM1.5G 1 Sun) reproducibly and consistently at our lab. Our study suggests the possibility of fabricating high-efficiency c-Si industrial cells successfully even in any small lab with low-cost lab equipment by taking care of each processing step scientifically with necessary corrective measures.

\section{Acknowledgements}

We would like to acknowledge the efforts of Nimisha S, Aditya D, Divya P and other colleagues at NCPRE for their assistance in characterization and processing. This work was carried out at the National Centre for Photovoltaic Research and Education (funded by the Ministry of New and Renewable Energy, Government of India) under the project no. 16MNRE002 at IIT Bombay.

\section{References}

[1] ITRPV 2017 Eighth edition www.itrpv.net/Reports/ Downloads/

[2] Basu P, Hameiri Z, Sarangi D, Cunnusamy J, Carmona E and Boreland M 2013 Sol. Energy Mater. Sol. Cells 117412

[3] Basu P, Sarangi D, Shetty K and Boreland M 2013 Sol. Energy Mater. Sol. Cells 11337

[4] Dastgheib-Shirazi A, Haverkamp H, Raabe B, Book F and Hahn G 2008 Proc. of 23rd European photovoltaic solar energy conference, $\mathrm{p} 1197$

[5] Duttagupta S, Lin F, Shetty K, Aberle A and Hoex B 2013 Prog. Phot.: Res. Appl. 21760

[6] Basu P, Sreejith K, Yadav T, Kottantharayil A and Sharma A 2018 Sol. Energy Mat. Sol. Cells 185406

[7] Hoornstra J, Van Strien W, Lamers M, Tool K and Weeber A 2007 Proc. of 22nd European photovoltaic solar energy conference, $\mathrm{p} 1586$

[8] Giesecke J, Schubert M, Michl B, Schindler F and Warta W 2011 Sol. Energy Mater. Sol. Cells 951011

[9] Basu P, Law F, Vinodh S, Kumar A, Richter P, Bottari F et al 2015 Sol. Energy Mater. Sol. Cells 137193

[10] Wong J 2013 Proc. of 39th IEEE photovoltaic specialists conference p 933 